\title{
Transfemoral Transcatheter Aortic Valve Implantation using a Long Sheath for Chronic Type B Aortic Dissection: A Case Report
}

\author{
Masaki Tsuda ${ }^{1}$, Yasuyuki Egami ${ }^{1}$, Koji Yasumoto ${ }^{1}$, Naotaka Okamoto ${ }^{1}$, Yasuharu \\ Matsunaga-Lee ${ }^{1}$, Masamichi Yano ${ }^{1}$, Masami Nishino ${ }^{1}$, and Jun Tanouchi ${ }^{1}$ \\ ${ }^{1}$ Osaka Rosai Hospital
}

June 4, 2021

\begin{abstract}
A 79-year-old woman with a history of open heart surgery presented with severe aortic stenosis (AS). Computed tomography (CT) showed chronic type B aortic dissection (TBAD) between the distal aortic arch and the left common iliac artery. After careful consideration, we planned transfemoral (TF)-transcatheter aortic valve implantation (TAVI) using a 20-Fr long sheath to minimize contact with the false lumen of the aorta. TAVI was performed under general anesthesia, guided by transesophageal echocardiography (TEE). A transcatheter aortic valve was successfully implanted. TEE, immediately after valve implantation, showed no remarkable changes in the descending thoracic aorta. Repeated post-procedural CT examinations showed no obvious changes in the aorta. The patient was stable without sequelae at the 12-month follow-up. This case demonstrates that TF-TAVI using a long sheath under TEE guidance can be a treatment option for patients with severe AS and chronic TBAD.
\end{abstract}

\section{Hosted file}

Main_document_of_TF-TAVI_Using_Long_Sheath_ver.3.doc available at https://authorea.com/users/ 311851/articles/524886-transfemoral-transcatheter-aortic-valve-implantation-using-along-sheath-for-chronic-type-b-aortic-dissection-a-case-report

\section{Hosted file}

Table_1.docx available at https://authorea.com/users/311851/articles/524886-transfemoraltranscatheter-aortic-valve-implantation-using-a-long-sheath-for-chronic-type-b-aorticdissection-a-case-report 


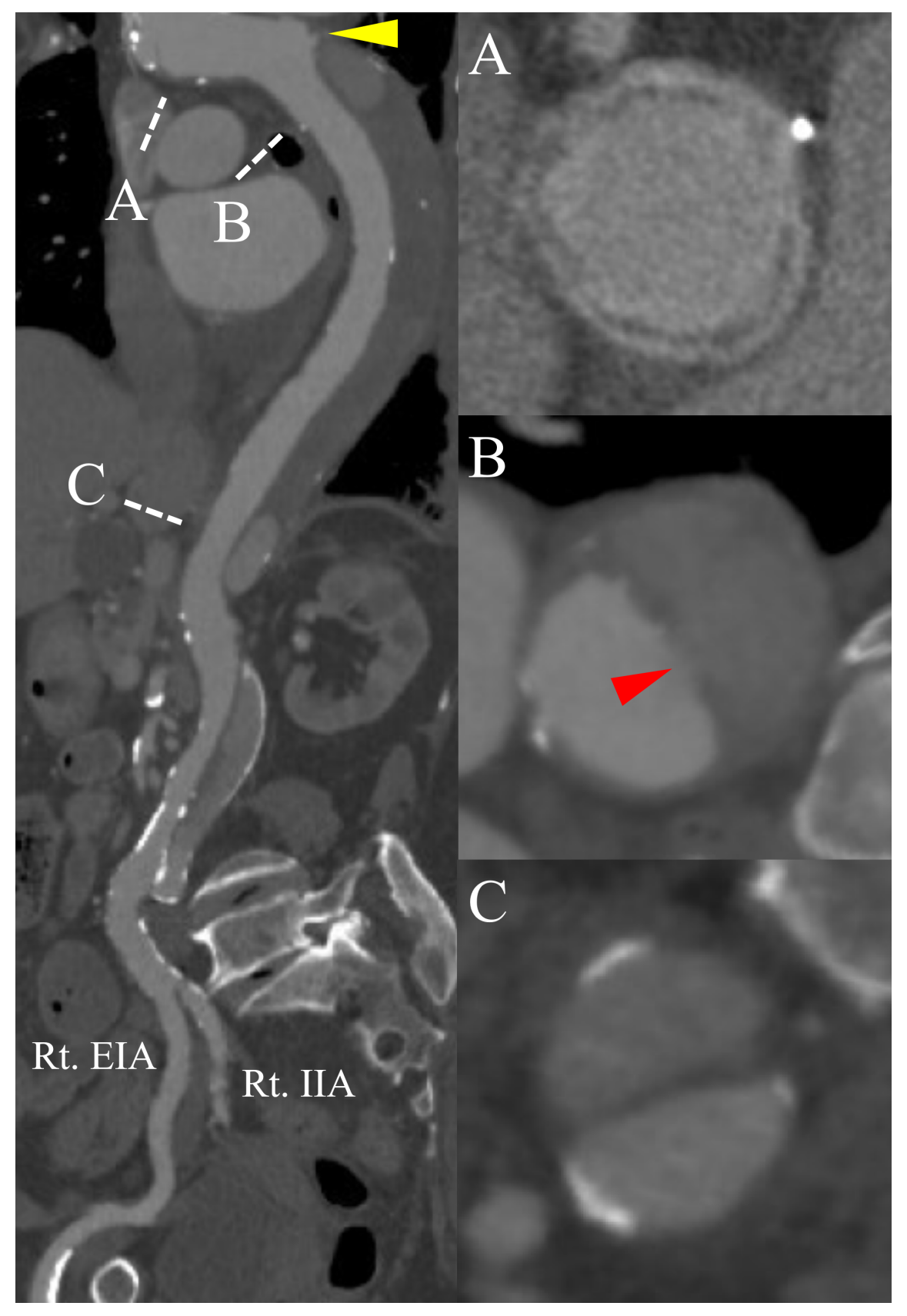



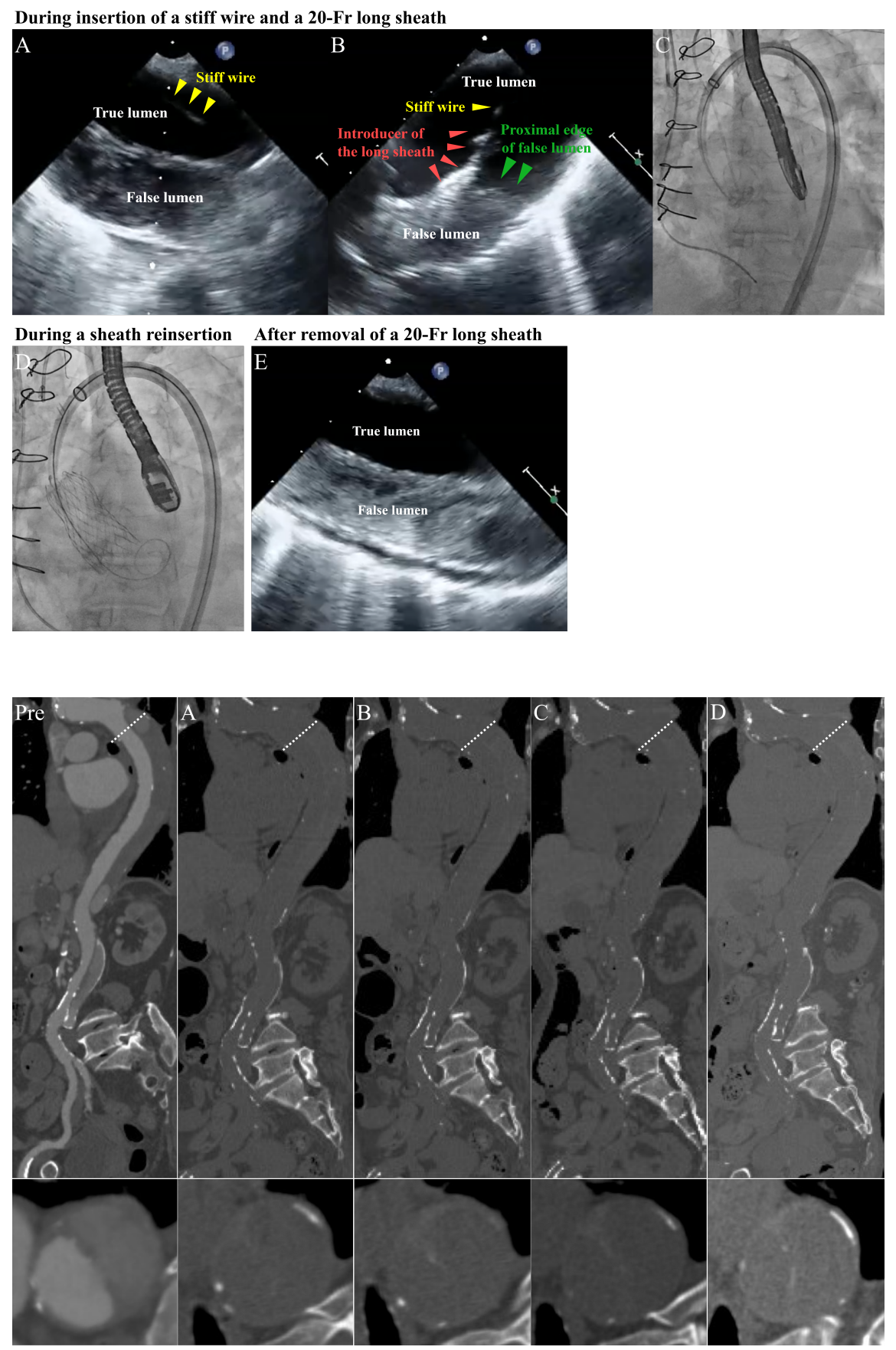